
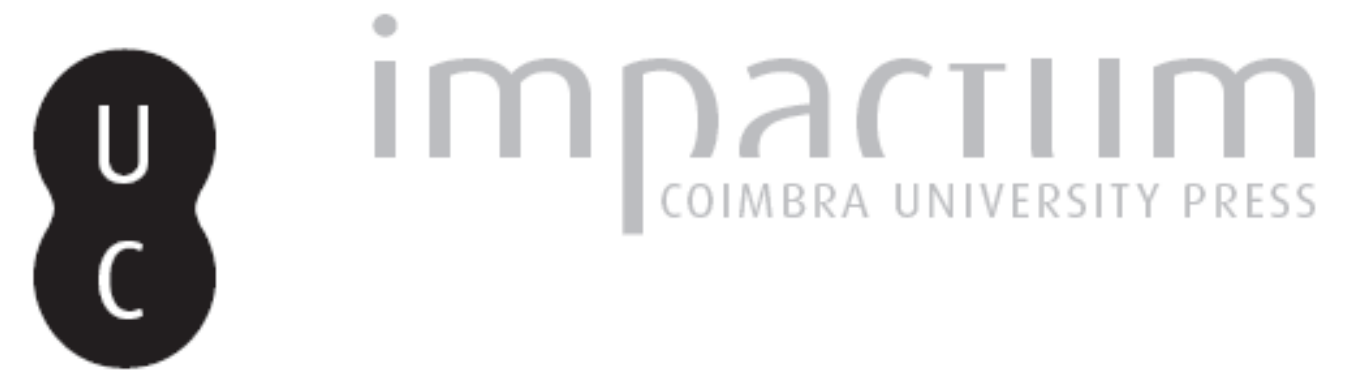

\title{
Fazer cidade sobre o sítio da cidade
}

\section{Autor(es): Santana, Paula}

Publicado por: Editorial do Departamento de Arquitectura

URL persistente:

URI:http://hdl.handle.net/10316.2/37475

DOI:

DOI:http://dx.doi.org/10.14195/0874-6168_4_8

Accessed : $\quad$ 26-Apr-2023 11:50:21

A navegação consulta e descarregamento dos títulos inseridos nas Bibliotecas Digitais UC Digitalis, UC Pombalina e UC Impactum, pressupõem a aceitação plena e sem reservas dos Termos e Condições de Uso destas Bibliotecas Digitais, disponíveis em https://digitalis.uc.pt/pt-pt/termos.

Conforme exposto nos referidos Termos e Condições de Uso, o descarregamento de títulos de acesso restrito requer uma licença válida de autorização devendo o utilizador aceder ao(s) documento(s) a partir de um endereço de IP da instituição detentora da supramencionada licença.

Ao utilizador é apenas permitido o descarregamento para uso pessoal, pelo que o emprego do(s) título(s) descarregado(s) para outro fim, designadamente comercial, carece de autorização do respetivo autor ou editor da obra.

Na medida em que todas as obras da UC Digitalis se encontram protegidas pelo Código do Direito de Autor e Direitos Conexos e demais legislação aplicável, toda a cópia, parcial ou total, deste documento, nos casos em que é legalmente admitida, deverá conter ou fazer-se acompanhar por este aviso.

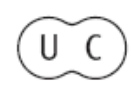




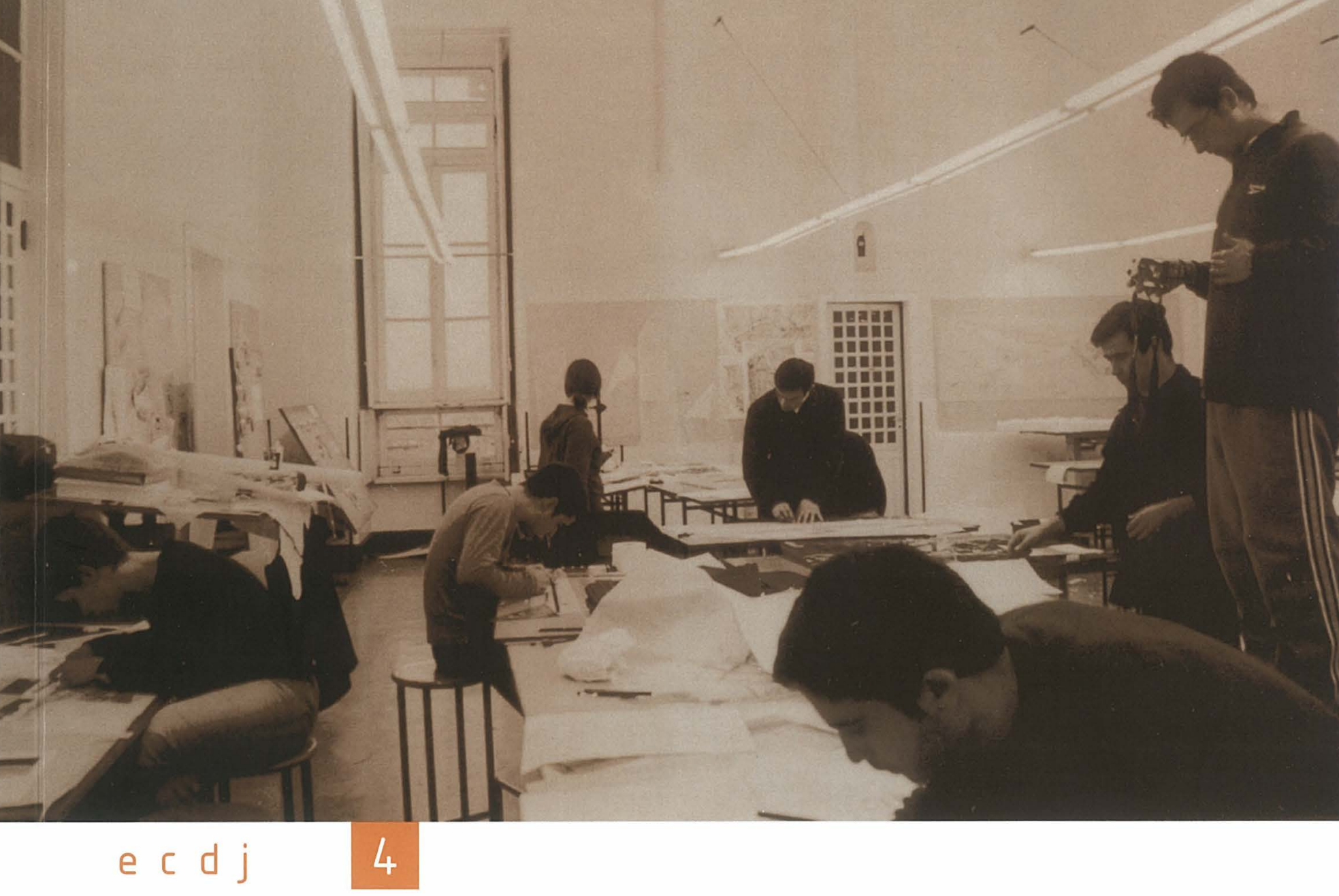

fctuc | departamento de arquitectura

coimbra: um novomapa

manuel gallego

workshop internacional de arquitectura

manuel solà-morales

manuel graça dias

гаúl hestnes fеггеiга

sergio fernandez

álvarosiza entrevista

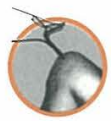




\section{fazer cidade sobre o sítio da cidade \\ paula santana}

\section{introdução}

"... a cidade é potencialmente o símbolo poderoso de uma sociedade complexa" (").

Para alimentar este conceito deve perceber-se que a cidade vive se oferecer segurança, se tiver um centro forte, se a "morte da distância" não vier a significar a morte da cidade.

\section{segurança}

> A cidade, na sua essência é o lugar seguro, onde se intensifica e aprofunda a experiência humana. O Homem torna-se urbano pela necessidade de comunhão de crenças, partilha de ideias e de bens mas, acima de tudo, porque ai encontra segurança. O sentido de urbanidade implica e implicou, desde o início, agregação, densidade, união contra o inimigo (que era exterior à cidade). Este facto marcava a forma: A cidade rodeava-se de poderosas muralhas e fechava-se, protegendo-se e protegendo os seus cidadãos.

> Hoje, a segurança na cidade procura-se na negação da própria cidade e materializa-se nos condomínios fechados. $\mathrm{O}$ edifícios voltam-se para os espaços centrais interiores, com os seus próprios serviços, comércio e cafés, transformando a cidade num arquipélago, condenando as ruas a serem apenas vias de acesso. A cidade resulta retalhada, ou seja no sítio da cidade confrontam-se micro espaços privados coalescentes com os espaços públicos mas protegidos deles por muros, não de delimitação mas de defesa.

Este é o cenário dos espaços novos da cidade, fundamentalmente localizados na periferia.

\section{a força do centro}

> A chave para o nosso conceito actual de cidade reside o argumento de que os vários lugares do lugar urbano que compõem a paisagem não podem ser dissociados. E, ainda, de que os resultados da justaposição das partes são, em si, tão determinantes para a imagem global da cidade como o são os próprios objectos justapostos e frequentemente são-no ainda mais ${ }^{(2)}$. 
> Quando, a partir dos anos cinquenta, se definiram os conceitos de "core", ou seja o coração - o núcleo genético e profundo das coisas, a razão última do seu modo de ser

e o de "cluster" ${ }^{(3)}-$ a associação de indivíduos que vivem conjuntamente,

cruzando seus fluxos vitais numa convivência que dá sentido ao indivíduo como parte

inseparável de um grupo humano mais amplo - tinha-se percebido que,

sem núcleo central forte gerador da dinâmica urbana, a cidade perdia força,

identidade e segurança. Muito embora pudessem existir outros centros,

o centro gerador da cidade deve ter a capacidade para agregar os indivíduos da sua periferia, orientando os fluxos e obrigando a densificar os vazios, ou seja, o processo da periferia que consolida o centro, partindo do princípio que o centro é espaço denso e selectivo.

Para que o todo seja mais do que o somatório das partes é preciso não só dar coerência à cidade antiga mas também reforçar o cenário físico, populacional e de actividades das "partes" que a envolvem, salvaguardando-se a qualidade de vida, para além de reforçar uma imagem ou uma forma que se possa admirar. Para que esses critérios sejam cumpridos,

há que corrigir debilidades físicas, demográficas, funcionais e produtivas do todo que é a cidade. No entanto, ao reorganizar a periferia, deve respeitar-se o papel do centro,

罗 tornando-o consistente.

A questão concreta que se coloca no caso da cidade de Coimbra é a de saber se a periferia é ou não uma projecção da cidade.

\section{a morte da distância pode significar a morte da cidade ?}

> Na passagem do século XX para o XXI as mudanças tecnológicas da era industrial para a era informacional - poderão trazer uma redesenhar geral dos mapas. Francis Cairncross chamou-Ihe a morte da distância ${ }^{(4)}$. Um novo tipo de sociedade e um novo tipo de cidade estão a chegar: Alguns dizem que já não é mais cidade, indiciam que a cidade irá morrer, tal como nós a conhecemos. Peter Hall afirma que um novo equilíbrio espacial baseado na relativa curta viagem para o trabalho e, presumivelmente, para outros locais de oportunidades estará na base da nova ordem e forma urbana, num futuro próximo. Importa reconhecer que as mudanças técnicas têm já, e poderão vir a ter ainda mais no futuro, implicações na vida urbana, principalmente pela oportunidade que oferecem à população de viver afastado da cidade e aí vir a encontrar trabalho, bens e serviços de que necessita, sem ter que percorrer longas distâncias. No entanto, existem actividades que precisam de estar agrupadas para se desenvolverem $e$ outras, ainda, que necessitam de contacto pessoal. 


\section{caso de estudo: coimbra}

> Coimbra é uma cidade que marca, por ser um lugar com carisma, por ser única, por ter uma espécie de energia. No entanto, no último século não foi suficientemente magnética para atrair pessoas e serviços em quantidade e qualidade que a colocassem em destaque no quadro regional. O paradoxo reside nisto - na cidade de Coimbra encontramos passado, adaptamo-nos às circunstâncias que a cidade nos oferece no presente, mas não conseguimos adivinhar futuro.

> Na entrada do século XXI, as debilidades da cidade de Coimbra revelam-se na forma descontínua, heterogénea, de limites imprecisos, na função pouco diversificada e no conteúdo dotada de um centro histórico fragilizado, porque cada vez mais inacessível, promíscuo, envelhecido, deformado com o qual competem centros secundários novos que pretendem afirmar-se e concorrer com o "coração" da cidade. No entanto, acreditamos que Coimbra tem potencialidades que podem vir a atenuar alguns dos efeitos negativos que resultam da anunciada "morte da distância", sendo para isso necessário actuar sobre as debilidades que existem na cidade.

> O desenvolvimento económico e tecnológico muda a face do território ou da paisagem, podendo desmembrar e, segundo alguns autores aniquilar as cidades.Contra essa tendência deve preservar-se ao máximo o sentimento de união ou agregação urbana, adaptando-a às novas condiçōes sociais e económicas. As principais dificuldades são políticas e sociais. Neste sentido, há que redesenhar Coimbra, enquanto cidade total - centro e periferia. Reencontrar a memória e a identidade sedimentadas nos seus edifícios históricos e museus carregados de significado, quarteirões antigos de encanto, modos de vida, tradições.

Tudo isso poderá ser cumulativamente e mutuamente reforçado se estes factos tiverem um cenário enquadrado ou emoldurado por um espaço de cidade que vá além do centro antigo e espaço consolidado. $O$ trabalho e as actividades continuarão congregadas na cidade e até no seu coração e os movimentos das populações continuarão a aumentar dentro e à volta desses centros, desde que a periferia se densifique e ofereça qualidade urbana aos seus habitantes.

\section{potencialidades}

> A cidade de Coimbra cresceu a partir dos elementos geradores - símbolos do poder, da cultura e da religião -, densificando o espaço, alternando com espaços verdes em equilibrio de proporções e construindo uma imagem de urbanidade. A cidade de hoje foi "inventada" na época medieval, com a instalação da Universidade. Apesar dos muitos acontecimentos posteriores, a permanência dos factos estabelecidos há muitas centenas de anos atrás continua a orientar o crescimento recente. A Alta, apesar dos dramáticos desaires dos anos 40 e 50 do século XX que a marcaram com cicatrizes profundas, continua a ser um exemplo de carácter que resulta da convergência das linhas de força, decorrentes da origem e função do aglomerado, reflectindo um eco imediato na topografia da colina. Adaptando-se às condições naturais e às circunstâncias sociais, económicas e culturais, o núcleo genético consolidou-se. 
O seu resultado é de uma harmonia de formas que perdura na memória dos homens, mesmo quando as condições sociais se alteram consideravelmente. Ainda na época medieval, a cidade desenvolveu-se para além das portas da cidade e as muralhas perderam a sua função. O comércio e os serviços administrativos desceram, encosta abaixo, para as áreas novas da cidade, olhando o rio.

> No casco antigo da Alta ou da Baixa, as ruas - rede de linhas de calcorreamento habitual, com uma textura especial de pavimento, fachadas impregnadas do tempo e dos tempos de fazer a cidade, partilhando uma estrutura particularmente clarifocadora, um conjunto de cheiros ou sons, de pormenores típicos anunciam a identidade de Coimbra. Também o rio Mondego teve uma qualidade particular capaz de o demarcar no espaço da cidade, principalmente quando ele era também uma via com concentração de actividades ao longo das suas margens, detentora de uma qualidade espacial e organizadora característica - a cidade antiga virada para o rio, em comunhão com o rio. Mais tarde, em consequência do aparecimento do comboio e da industrialização, a cidade voltou costas ao rio, privilegiando a estrada nacional (rua Fernão de Magalhães), ao longo da qual o edificado de ergue marginando a nova via. Quebrou-se, desta forma, a relação que antes a Baixa tinha ganho com o rio. $\mathrm{O}$ rio teve força agregadora no passado e hoje deve recumprir-se o seu desígnio. No centro ainda existem espaços que se podem considerar uma síntese da qualidade e do carácter da vida urbana: proporção, elegância e média densidade, a par do requinte dos jardins público com vegetação adequada.

> A força e potencialidade da imagem da cidade está no coração da cidade: a Universidade. A sua forma única, a sua função, a sua localização no cimo da colina, a sua exposição à cidade, a visibilidade da sua Torre a grande distância, conferem-lhe o título de elemento marcante. Visível de dia e de noite, de perto e de longe, inconfundível pela sua forma, profundamente ligada à história e às tradições da cidade. É dificil pensar na cidade sem que este edificio nos venha à imaginação ${ }^{\text {(ต) }}$.

\section{debilidades}

> A inexistência de uma política de solos em Coimbra afasta para áreas cada vez mais longínquas os habitantes, muito para além das portas da cidade, ou então multiplicam-se os andares para rentabilizar o terreno, cada vez mais raro. A periferia tem vindo a crescer de forma desordenada, sendo visivel o carácter de baixa densidade, falta de hierarquia de vias, desarticulação dos espaços residenciais, dispersão. As características da periferia revelam-se como negativo da essência urbana. É como se a ocupação desses espaços fosse realizada por pessoas evitando-se umas às outras e fazendo de contas que estão sozinhas.

O resultado é a antítese directa da "essência" do urbano. Na periferia de Coimbra verifica-se o isolamento físico e o isolamento psicológico. No sentido oposto está o centro como um espaço essencialmente urbano, mas fragilizado, impondo-se como produto humano. 
Coimbra é, por isso, o resultado de uma desarticulação entre as duas peças da cidade: o centro e a periferia. $O$ que se conclui é que centro e periferia são espaços que se tocam mas não se complementam e que as debilidades da periferia encontram ecos da sua desorganização no centro.

> Em Coimbra, a periferia dificilmente poderá ajudar a reforçar o centro se não acontecerem alterações nas forma ou dimensão física, social e psicológica. Por exemplo, o centro é invadido por um tráfego que já não tolera quer pela intensidade quer pelas características de traçado das suas vias. Algumas destas debilidades decorrem das características do tráfego que no momento actual apresenta duplo papel na organização (?) da cidade. Se, por uma lado, o espaço urbano é percorrido em todos os sentidos - criando tráfegos de atravessamento indiscriminados e sem hierarquia, transformando a cidade antiga num corredor-, a todas as horas e por motivos cada vez mais variados, por outro lado existe o prenúncio da "morte da distância" e os constrangimentos decorrentes para o futuro da cidade.

Assim, um dos grandes problemas de Coimbra é a desadequação da rede viária e de transportes públicos ao tráfego urbano, quer o que se processa dentro da cidade quer o de atravessamento da cidade. Se, por um lado, Coimbra sofre de deslocações para as áreas suburbanas ao fim do dia, ela constitui-se, também, como corredor para quem se desloca entre espaços de um e outro lado da cidade. Este é um dos resultados da má gestão urbanística da periferia, por um lado e da falta de uma política de solos urbanos municipais, por outro. Em Coimbra, o transporte público não pode competir com o transporte privado, principalmente quando as deslocações se verificam entre os subúrbios. À medida que as casas e os empregos se descentralizaram, mais e mais viagens foram transferidas do transporte público para o privado. As políticas de ordenamento do território devem fazer os possíveis para desenvolver espaço de residência de densidade média perto dos lugares de trabalho e compras e acessiveis a pé ou de bicicleta ${ }^{(6)}$.

> A grande alteração à força da imagem da cidade, nos últimos anos, resulta do crescimento periférico plasmado nas áreas rurais periféricas, mas em alguns espaços agarradas ao centro medieval. A expressão visual do núcleo antigo, é fragilizada pela falta de traços relevante nos seus arredores, e por isso, cada vez mais tem vindo a acontecer impedimentos à organização da imagem da cidade: confusões, pontos flutuantes, fronteiras mal definidas, isolamentos, quebras na continuidade, ambiguidades, ramificações, falta de símbolos ou diferenciações, condições apontadas por Kevin Lynch (1988) como fundamentais para a percepção do espaço urbano ou para organização de uma imagem urbana. 


\section{capacidade de alterar as debilidades}

> A segurança está intimamente relacionada com a identidade, afastada da concepção que inicialmente gerou a cidade mas profundamente ligada a ela. O que hoje deve ser oferecido ao cidadão já não é a protecção ou resguardo contra o inimigo, mas ambiente urbano, protecção psicológica, a partir de elementos de referência consistentes e marcantes que estruturem o espaço e Ihe dêem coesão: elementos simbólicos, elementos singulares, densidade de construção, vias, etc, qualidade urbana realmente total, isto é, uma cidade concebida para todos os sentidos e todos os instantes.

Se em Coimbra se reforçar a imagem pública - preservação de elementos marcantes, o desenvolvimento de uma hierarquia visual de ruas, o estabelecimento de unidades temáticas para bairros, a criação ou clarificação de pontos fulcrais da periferia e a densificação destes poderá vir a surgir uma nova concepção de cidade, como uma forma total visível. O objectivo não é a forma em si, mas a qualidade de uma imagem mental. Não pode continuar a perpetuar-se a ideia errada de tentar reencontrar a urbe clássica ou medieval por incapacidade de produzir uma cidade contemporânea ${ }^{(7)}$. Coimbra tem crescido em dimensão populacional e de espaço e há que ter a convicção que a periferia dita uma série de imperativos e é, também, cidade.

pensar a cidade de coimbra no presente, para o futuro - propostas dos arquitectos: por uma nova ordem urbana

> Genericamente, as propostas apresentadas para o espaço periférico vinculam-lhe a instalação de actividades que antes eram reservadas ao centro da cidade e afirmam uma densidade média para o espaço de periferia de Coimbra. Duas premissas: 1. a construção deve ser contida no equilibrio de formas e funções; 2 . deve ser projectado o corpo da periferia, tendo como ponto de partida o centro e a sua identidade. Pressupõe-se que, nas periferias, os ritmos de vida são complementares aos do centro da cidade, sendo assim, o que se pretende é

"reestrurar o centro histórico partindo da periferia", para "Amanhã reestruturar a periferia partindo do centro histórico" ${ }^{(8)}$. As escalas utilizadas são de três níveis: grande, intermédia e pequena. A primeira, pontualista; a segunda estabelecendo a ligação entre as operações pontuais e as operações mais vastas de restruturação de conjuntos dos quarteirões; a terceira oferecendo o programa para toda a área envolvente ao núcleo central consolidado

\section{linhas de força das propostas apresentadas}

a) Reforçar o papel da periferia para consolidar o centro: A procura do reforço do potencial demográfico e económico através do reforço dos equipamentos, da melhoria dos serviços e da acessibilidade, enfim, a procura de um nova era no equilíbrio da cidade, parecem ser objectivos de todas as propostas apresentadas.. Deve ser prioritária a (re)organização das zonas já construídas, embora por vezes de baixa densidade, em vez de se construir em novas zonas, cada vez mais afastadas da cidade. 
> b) Caracterizar a imagem da cidade no seu todo: criando ambiente e impacto visual na periferia para poder reforçar a imagem do centro. A ideia central é que a cidade constitui um todo integrado, e os meios que temos vindo a referir inserem-se na arte da união e ligação desse todo num padrão coerente. Um panorama vasto causará, por vezes, um caos, ou será a expressão de solidão, mas um cenário bem organizado parece ser o principal de uma cidade agradável.

Para isso pretende-se acabar com uma paisagem descaracterizada porque não pertence nem à cidade nem ao campo. Nesse sentido, são apresentadas propostas que vinculam a colmatação de áreas de vazio: criar uma lógica urbana através de linhas de amarração.

Alguns programas apresentam a existência de percursos através de zonas de compreensão e de vazio, por vezes até de abandono, contraste entre espaços delimitados, alternância de situações de tensão e momentos de tranquilidade. Talvez com mais evidência na proposta coodenada por Solà-Morales, "aproximar a habitação da tranquilidade do Choupal retirando-a dos viadutos da IC2 onde a chave da intervenção será "mistura(e) radicalidade e bom senso ... descobrindo novas relações entre o existente e o novo" ${ }^{(9)}$. Mas também o grupo dirigido por Siza Vieira desenha um espaço de habitar e de equipamentos respeitando o encontro com a paisagem local (enfiamento da estrada das Lajes).

> Criar novas centralidades: (Re)organizar o crescimento na periferia encontrando novos centros. Densificar pontualmente alguns espaços, encontrar o sentido do lugar ${ }^{(10)}$, são propostas formuladas em quase todos os programas. Por exemplo, o grupo coordenado por Graça Dias apresenta como resultado para a sua área de intervenção a criação de novas centralidades, aglutinando áreas de dispersão. Genericamente, pretende-se criar animação e intensidade urbana através da presença de comércio e de equipamentos públicos nos locais até aí monofuncionais (11). Por isso, em todos as propostas são apresentados espaços multifuncionais. Embora tratando-se, essencialmente, de criar uma lógica de cidade na periferia contida pela circular, o que se revela nos trabalhos apresentados é que houve a preocupação de assinalar o território pela permanência, mais do que pela circulação. Entende-se claramente que a construção urbana tem por base não só a construção de infra-estruturas urbanas básicas, fundadas particularmente nos novos sistemas de transportes, mas também no desenvolvimento comercial e residencial que seguem as oportunidades criadas pelas primeiras.

Os transportes têm vindo a provar ser os fazedores de cidades. Por isso se entendeu reforçar as ligações entre as duas margens (duas novas pontes de circulação rápida e duas pedonais), desenhar o interface rodo-ferroviário e metropolitano ligeiro de superfície, criar um corredor de tráfego rápido que liberte os talvegues e crie novas acessibilidades respeitando a natureza. As opçōes que foram tomadas respeitaram, genericamente, a ligação entre o desenvolvimento e o ambiente (o impacto do tráfego no ambiente acessos e padrões de circulação),

a preservação do meio natural na cidade e à volta dela, a importância das redes de infra-estruturas. 
> Criar linhas de amarração e nodalidades: Articulação entre as circulações e as permanências. Todas as propostas têm como base de trabalho a lógica da circular, os grandes traçados que têm vindo a ser executados pela CMC. Na verdade, todas as propostas tiveram a preocupação de qualificar os nós, criando lógicas de cidade em espaços de ocupação difusa.

Segundo Soja (1989), a nodalidade define e dá substância à especificidade urbana com distinção social e propósitos espaciais. A nodalidade confere urbanidade, dando forma material ás relações sociais essenciais. O espaço nodal é urbanizado através da interacção entre dois processos intercativos: o de sobrevivência e o de adesão ${ }^{(12)}$..

\section{respostas para a cidade de coimbra}

> A organização da cidade, através da (re)organização de um conjunto de percursos, reveste-se de uma crescente importância para Coimbra, para que possa responder com eficácia à contemporaneidade. Aumentar a mobilidade e as relação com o exterior respeitando o ambiente da cidade (diminuir o tráfego de atravessamento, por exemplo) são propostas apresentadas, tendo como linha de força a realização de nós de interconexão. Por exemplo, algumas propostas vão no sentido da concentração e interconexão de novas centralidades em torno dos sistemas de transportes. O interface rodo-ferroviário e metropolitano de superfície é apresentado como um importante nó urbano, funcionalmente vital para as mudanças de transporte do utente da cidade e também devido à impressão visual causada pela Praça Porta Norte da cidade. A exemplo de outras cidades ${ }^{(13)}$, acredita-se que o investimento a ser feito nas infraestruturas de transportes trará marcas positivas na cidade de Coimbra.

> A circular, entra nos programas como um instrumento que deve ser

> "adaptado ao urbanismo evolutivo, complexo, precisamente na medida em que se situa numa escala estratégica e que abre possibilidades múltiplas de adaptações concretas" (14)

> funcionais e de relação. Para além da circular, outras vias entram nos programas com a finalidade de implantar uma infra-estrutura de transporte, orientar as construções e as actividades, articular bairros, oferecer ou implementar a comunicação. Por exemplo, a organização do trânsito em consequência da criação da circular e da fragmentação da cidade em unidades funcionais identificáveis (densificar pontualmente ao longo da circular), permitirá limitar o movimento de veículos em cada área apenas aos que de facto se justifica que aí estejam, eliminando-se, em grande parte, os fluxos de atravessamento que caracterizam e debilitam a cidade de Coimbra.

> As pontes devem reforçar a amplitude da imagem do núcleo central dominado pela colina da universidade e encimado pela torre. Ao projectar as pontes a duas ou mais cotas pretende-se estabelecer sensações dinâmicas, organizadas numa linha melódica que coloque em destaque imagens, acontecimentos e características diferentes ao longo dos caminhos. Se as pontes pedonais podem oferecer, de um modo geral, sensaçōes de intimidade, de aconchego, de privacidade, de comunhão com o espaço imediato, a Ponte Europa, de caracter pouco urbano e mais rodoviário - até ao cruzamento das Lajes está projectada (e já em construção) acima do nível do solo o que confere sensações de domínio ou superioridade ou, pelo contrário, de 
exposição e de insegurança. Mas o acto de a descer, utilizando a circulação periférica entrar na cidade oferece, por outro lado, uma sentimento de vantagem, uma boa posição para se poder olhar a colina da Universidade. E à medida que nos aproximamos do solo, tem-se a noção de baixar ao encontro daquilo que conhecemos Para além das pontes, os nós, não só estruturam a região internamente como também intensificam a identidade do todo, enriquecendo e aprofundando o seu carácter.

> As vias são transformadas em lugares chave da transformação. Grande aposta na miscigenação funcional das vias: reinventar o boulevard? ${ }^{(15)}$. Os espaços de lazer são uma constante na "reutilização" ou reorganização da periferia. Também em Coimbra se pretende reconquistar vazios ao longo do rio e da linha de caminho de ferro, operação que mistura negócios e encontros profissionais com o lazer e cultura: museus, actividades náuticas, cafés, teatro, hotéis, restaurantes, palácio de congressos, alguns imóveis e escritórios. Noutros espaços são sugeridas também, com frequência, equipamentos destinados ao lazer: centros culturais e de lazer, casino, parque de campismo, etc. Em alguns casos, estas unidades funcionais podem ter um efeito de catálise. Exemplifique-se com o Parque Jaime Cortesão a construir numa área disponível de "vazio" e que irá decerto provocar a qualificação de vários blocos de habitação situados nas proximidades. Ao mesmo tempo, o Museu da Ciência pode também gerar fluxos que atrairão os estabelecimentos comerciais e ajudarão a desencadear mecanismos de valorização.

\section{> conclusão}

A cidade funciona na base de lógicas e de racionalidades múltiplas, eventualmente contraditórias e, por isso, a cidade é complexa e não apenas complicada, o que implica que ela se constitui como um sistema aberto, que os seus equilíbrios são instáveis, que as variações menores podem engendrar mudanças consideráveis e que as evoluções são geralmente irreversíveis ${ }^{(16)}$. Construir no construído, fazer cidade sobre a cidade são em síntese alguns dos resultados do Workshop um novo mapa para a cidade de Coimbra: densificar nuns sítios e qualificar noutros, criar vias transversais, desencravar bairros e ligá-los com o meio ambiente, melhorar as pequenas funcionalidades através da criação de polos de centralidade que aglutinem polos de dispersão, inventar uma nova estética dos espaços públicos e exteriores, reafectar e requalificar os espaços tornados vazios ou obsoletos pelas mutações técnico-económicas, dispor de reservas fundiárias para poder atrair novas oportunidades e tornar a urbanização compatível com os princípios de um desenvolvimento sustentável, para que a cidade possa responder a uma procura residencial cada vez maior e mais diversificada e, em simultâneo, possa oferecer equipamentos educativos, culturais, desportivos e comerciais de qualidade. Se estes pressupostos forem cumpridos e se forem conectados com os valores do património e da identidade (perdida ? ${ }^{(17)}$, Coimbra poderá vir a reencontrar uma imagem de marca e de qualidade. 
> Os programas apresentados para a auréola à cidade consolidade de Coimbra inscrevem-se na paisagem da cidade e dão força e coesão ao núcleo genético porque, genericamente, respeitam os sítios $\theta$ o património paisagístico. Por exemplo, a relação da cidade com o rio vê-se claramente enquadrada e reforçada.

> Em sintese, pode afirmar-se que os resultados apresentados tiveram em conta princípios de respeito pelas paisagens, a adequação à geografia do lugar, a tomada em consideração do sítio. Se Coimbra passar para o observador como um conjunto e não como um somatório de elementos isolados, a imagem ganha maior consistência e reforça-se, garantindo, desta forma, o sentido de segurança e de intensidade das experiências humanas.

Chegou "a vez da periferia conferir algum sentido ao centro" ${ }^{\text {"(1) }}$ fazendo reemergir a condição de Coimbra, cidade única, onde não se perfila a morte da cidade pela morte da distância, propondo-se para isso um "novo mapa ... que procura resgatar para si uma condição contemporânea" (19). - É esse, finalmente, o inadiável desafio de Coimbra. Fazer-se cidade sobre o sítio da cidade Bandeirinha, J. Novos mapas para velhas cidades, in: Novos mapas para velhas cidades, ecdj, Novembro, 2000, pp. 80-85 Benevolo, L, A cidade e o arquitecto, Arte e comunicaçắo, ediçōes 70, Lisboa, 1984 Canto Moniz, G., Uma estaçăo intermodal sobre o apeadeiro de Coimbra B in: Novos mapas para velhas cidades, ecdj, Novembro,

Castells, M. The power of identity. The information age: economy, society and culture, volume II, Blackwell, Oxford, 1997. Correia, N., O resto da Periferia, in: Novos mapas para velhas cidades, ecdj, Novembro, 2000, pp. 102-105 Cullen, G., Paisagem Urbana, Arquitectura e Uebanismo, ediçōes 70, Lisboa, 1996 Grande, N., Coimbra como projecto urbano, in: Novos mapas para velhas cidades, ecdj, Novembro, 2000, pp. 50-55. Linch, K., A imagem da cidade, Arte e comunicaçăo, Lisboa, ediçōes 70, 1988. Peter Hall, Cities in Civilization. Culture, innovation, and urban order, Phoenix, Londres, 1998. Soja, E., Postmodern Geogarphies. The Reassertion of Space in Crtitical Social Theory, Verso, Nova lorque, 1989 Soja, E., Thirdspace. Journeys to Los Angeles and other real-and-imagined places, Blackwell, Massachusset, 2000 Solà-Morales, I., Diferencias. Topografia de la arquitectura contemporánea, editorial Gustavo Gili, Barcelona, 1995. 